\title{
Interlanguage Development in Speech Act Strategy Choices: Apologies by Norwegian Pre- and In-service Teachers of English
}

Anna Krulatz

Norwegian University of Science and Technology (NTNU)

\begin{abstract}
Previous research on interlanguage pragmatics suggests that performance of apologies in a second language can pose challenges for adult language learners. This paper reports on a study that examined the variation in the use of apology strategies in response to discourse completion tasks produced by 110 Norwegian pre- and in-service upper-elementary English teachers at three different proficiency levels. The apologies were classified using coding procedures adopted from Blum-Kulka and Olshtain (1984), Blum-Kulka, House and Kasper (1989) and Rose (2000). The data were analyzed using descriptive and inferential statistics, and the findings are illustrated with selected examples from the data. One-way ANOVAs and Chi-square tests were run to determine if the differences between the groups were statistically significant. No significant differences in the production of the main apology and the employment of lexical intensifiers were found. However, developmental patterns were revealed in the use of apology modifications (adjunct strategies), particularly in the number of and variations of modifications, with participants of higher proficiency levels employing significantly more varied and extensive modifications.
\end{abstract}

\section{INTRODUCTION}

This paper reports on a study that examined the variation of strategies used in the performance of the speech act of apology by pre- and in-service English as a foreign language (EFL) teachers in Norway. The study is rooted in the tradition of interlanguage pragmatics research, as well as research on multilingualism. Consequently, the notion of the native speaker as the norm for linguistic behavior in a second (L2) or consecutive language is refuted, and no attempt is made to draw a comparison between native and non-native speaker performance. Instead, the study explored the range of speech act strategies used by groups of non-native speakers of different proficiency levels. Thus, the goal was not to focus on errors 
and deficits among non-native speakers as compared to native speakers (Cook, 1999), but rather to uncover developmental patterns. Following Llurda (2004), the underlying assumption was that non-native users of English are "entitled to the authoritative use of a variety of the language that belongs to them" (p. 320). The participants included three groups of language users: pre-service upper-elementary EFL teachers at the end of their first year of a teacher education program; pre-service upper-elementary EFL teachers at the end of their second year of a teacher education program; and in-service, practicing upper-elementary EFL teachers nearing completion of a 30-credit EFL endorsement course.

\section{LITERATURE REVIEW}

\subsection{Pragmatic development}

The ability to perform speech acts, e.g., requests, invitations, compliments or apologies, is one of the components of communicative competence (Bachman \& Palmer, 2010). Interlanguage pragmatics is the domain of applied linguistics concerned with the development of the ability to successfully participate in linguistic interactions, including production and the effect on the recipient (Kasper \& Rose, 2002). Research suggests that L2 learners go through developmental stages in attaining pragmatic competence, with beginning learners relying on formulaic expressions and selecting fewer politeness markers. As L2 develops, learners reach higher levels of linguistic control, and are able to produce more complex speech acts that are contextually appropriate and more in line with target language norms (Kasper \& Rose, 2002). However, attainment of pragmatic ability is highly variable and depends on factors such as the type and amount of language exposure (Bardovi-Harlig \& Hartford, 1996; Kim, 2000), presence or absence of pragmatics-focused instruction (Ohta, 1995; Ishihara, 2010), and individual learner differences such as motivation (Takahashi, 2001).

\subsection{Apology}

Apologies are face-supporting speech acts (Brown \& Levinson, 1978, 1987) defined as "[a] type of remedial work, action taken to change what might be seen as an offensive act into an acceptable one" (Fraser, 1981, p. 259). Apologies are post-event acts (Leech, 1980) used to make up for a previous action that has been perceived, by either the speaker or the hearer or 
both, as offensive or harmful. They constitute an acknowledgment that an offense has been committed and, potentially, an assumption of responsibility for the offense, as well as an attempt of repair on the part of the speaker. As a politeness strategy, apologies are also a manifestation of one's sociolinguistic ability, defined as one's "skill at selecting appropriate linguistic forms to express the particular strategy used to realize the speech act" (Cohen, 1996, p. 22). Olshtain and Cohen (1986) propose a set of formulae that can be used to express an apology, referred to as speech act set: (1) an expression of an apology, (2) an explanation or account of the situation, (3) an acknowledgment of responsibility, (4) an offer of repair, and (5) a promise of forbearance (Olshtain \& Cohen, 1986). Any of these formulae can be used in isolation, or they can be combined to intensify the apology, but the extent to which the different formulae are used varies cross-culturally and cross-linguistically.

The first formula, an expression of apology, can be performed using explicit illocutionary force indicating devices (IFIDs), which indicate the illocutionary force of an utterance (Searle, 1969). IFIDs in English include word order, performative verbs, the mood of the verb and intonation. In the case of apologies, IFIDs can be performed as formulaic, conventionalized expressions of regret such as I am sorry, I apologize, or Please excuse. Olshtain and Cohen (1986) further distinguish subtypes of an expression of apology, namely an expression of regret, an offer of apology, and a request of forgiveness. Similarly, responsibility can be acknowledged in a number of ways. The offender can accept the blame, express self-deficiency, recognize that the apology is due, or express a lack of intent. The last two sub-formulae are situation specific. For instance, an offer of repair is only relevant if some type of damage occurred, and an offer of forbearance is made if the offense could have been avoided.

The second apology formula is an explanation or account of the situation. It can serve as the sole expression of an apology, or it can be used in conjunction with one of the other strategies. This strategy is typically used if external factors over which the offender had little or no control led to the offense (Olshtain \& Cohen, 1986). Explanations can be specific to the situation (e.g., I didn't hear my alarm this morning) or expressed using a generalization that is relevant to the situation at hand (e.g., You know how hard it is to get up on a rainy day) (Blum-Kulka et al., 1989). 
When the offender specifically recognizes the responsibility for the offense, acknowledgment of responsibility is used. The offender can use a direct strategy and accept the blame or choose an indirect strategy such as an expression of self-deficiency, a recognition that the other person deserves apology, or an expression of lack of intent (Olshtain \& Cohen, 1986). Whether expressed directly or indirectly, taking on responsibility is face-threatening to the speaker, but can nonetheless "be placed on a continuum from strong self-humbling [...] to complete and blunt denial of responsibility" (Blum-Kulka et al., 1989, p. 207). In other words, there are various degrees of taking on the responsibility, including an explicit self-blame (e.g., It's entirely my fault), an expression of self-deficiency (e.g., I am completely useless), and denial of fault (e.g., It's not my fault).

If physical injury, damage or inconvenience has been caused, the speaker may opt to issue an offer of repair in an effort to compensate for the damage (Olshtain \& Cohen, 1986). Finally, a promise of forbearance is an indirect way to admit guilt, and it can be used when the offender has a strong feeling of responsibility, or when the offense could have been avoided (Cohen, Olshtain, \& Rosenstein, 1986; Blum-Kulka et al., 1989).

In addition to employing one or several of the strategies discussed above, an apology can be intensified or downgraded. An intensification can be performed using an adverbial (e.g., I strongly apologize) or a repetition within the IFID (e.g., I am really really sorry), or it can be added externally to the IFID by expressing a concern to the hearer or employing several strategies together. Alternatively, an apology can be downgraded by minimizing the offense or questioning the preconditions of the apology (e.g., It's not such a big deal) (BlumKulka et al., 1989).

\subsection{Apologies in English and Norwegian}

Empirical studies of strategies used to carry out native English apologies have been conducted by Holmes (1990), Suszczyńska (1999), Deutschmann (2003), and Ogiermann (2009). In New Zealand English, an expression of regret and an explanation or an account of what happened seem to be the preferred strategies and are the only strategies that occur alone (Holmes, 1990). A strong preference for routinized IFIDs in English, in particular an expression of regret, was also confirmed by Ogiermann (2009). In Holmes's corpus, over $50 \%$ of the apologies consisted of a combination of two or more strategies (p. 169-170). 
Suszczyńska (1999) found a strong preference for IFIDs in American English, with an overwhelming majority being an expression of regret, and argued that this is due to the wish to maintain the social distance between the interlocutors. Suszczyńska also noted that her English-speaking subjects, in comparison with Poles and Hungarians, displayed a lack of willingness to assume responsibility. Similar findings were reported by Deutschmann (2003), who concluded that in British English, strategies which minimize the offense were chosen four times as often as other strategies, suggesting a strong tendency to save face.

According to Awedyk (2011), IFIDs also appear to be the most frequently chosen apology strategy in Norwegian. In his data, IFIDs constituted $83 \%$ of the apologies, and included expressions of regret, offers of apology, and requests for forgiveness, as well as three categories not present in the classification proposed by Olshtain and Cohen (1983), namely conciliatory expressions, softeners or intensifiers, and foreign words (i.e., sorry) (Awedyk, 2011). Overall, Awedyk concluded that Norwegians show a preference for negative politeness strategies, i.e., showing consideration for people's need to remain unhindered, and highly conventionalized apologies, and that they tend to minimize their responsibility when they are at fault.

\subsection{Interlanguage and developmental studies}

A number of studies have examined non-native (L2) English apologies, including apologies produced by native speakers of Hebrew (Cohen et al., 1986), Dutch (Trosborg, 1987), Japanese (Kondo, 1997), Catalan (Sabaté i Dalmau \& Curell i Gotor, 2007), and Turkish (Aydin, 2013). These studies found both similarities and differences between native and nonnative speaker apologies. For instance, Cohen et al. (1986) concluded that advanced learners of English select apology strategies, including an expression of apology, an explanation, an expression of responsibility, a repair and a promise of forbearance, in a way similar to native speakers. However, the study found important differences in the use of apology modifications, e.g., the intensity of the apology and minimizing the responsibility or the offense. Sabaté i Dalmau and Curell i Gotor (2007), on the other hand, concluded that Catalan learners of English employed IFIDs more frequently than native speakers of British English. Aydin (2013) obtained similar findings with native speakers of Turkish. 
Although its body is growing, research on pragmatic development is still in its beginnings (Rose, 2000; Kasper \& Rose, 2002; Rose, 2009). The existing studies conclude that learners go through developmental sequences as they move towards native-like production and that the competent use of apologies increases with language proficiency (see, for example, Maeshiba, Yoshinaga, Kasper, \& Ross, 1996; Rose, 2000). Research also suggests that second language learners may encounter difficulties with intensification of apologies (Márquez Reiter, 2000). However, the number of studies that examined interlanguage apologies is still relatively small, with no former study having examined apologies produced by L2 English learners whose first language (L1) is Norwegian. The present study attempts to bridge this gap.

\section{METHODOLOGY}

\subsection{Research questions}

Aiming to contribute to the growing body of research on the development of interlanguage apologies, this study focuses on the use of apology strategies in English by three groups of native Norwegian speakers: two groups of pre-service upper-elementary teachers majoring in English, and one group of in-service upper-elementary teachers of English. The research questions are based on Cohen and Shively (2007) and Rose (2010):

1. What types of apology strategies, including the five main apology formulae (Olshtain and Cohen, 1986) and apology intensifications, are used by pre- and in-service EFL teachers who are native speakers of Norwegian?

2. Is there a difference in apology performance between pre-service teachers who have completed 30 credit units, pre-service teachers who have completed 60 credit units, and in-service teachers?

3. Is there evidence of influence from L1 Norwegian in the English apologies by Norwegian EFL teachers?

\subsection{Participants}


The 110 respondents in this study included 34 pre-service upper-elementary English teachers at the end of the first year of study (Group 1), 37 pre-service upper-elementary teachers at the end of the second year of their program (Group 2), and 39 in-service upperelementary English teachers nearing the completion of 30 credits of English training (Group 3). In addition, to account for possible cases of cross-linguistic influence, control data in Norwegian L1 were collected from 25 informants. All participants were native speakers of Norwegian. The in-service teachers were enrolled in a one-year English endorsement course at a teacher's college in Norway, which is equivalent to 30 ETCs. They were all teachers of English who obtained their teaching degrees before the implementation of the revised national curriculum referred to as The Curriculum for Knowledge Promotion in Primary and Secondary Education and Training (Utdanningsdirektoratet, 2006), which introduced a requirement of 60 ETCs in the area of specialization for upper-elementary teachers. Consequently, the in-service teachers in the study had been teaching English without a teaching certificate in the subject. The data from this group were collected at the end of the second semester when they were about to graduate from the EFL endorsement course. The pre-service teachers were students enrolled in the first and second year, respectively, of a teacher training program at the same institution, and were all English majors. These students obtain 30 credit units per year. The data from these groups were collected at the end of the second semester in the academic year, i.e., when the groups have nearly completed their coursework and the required ETCs (30 and 60 units respectively). These groups had also completed a teaching practicum in Norwegian public schools (six and 12 weeks respectively). Explicit focus on pragmatics and politeness norms in English is not a part of the core curriculum in any of the courses.

\subsection{Materials and procedure}

The study employed a discourse completion task (DCT) as a data collection tool. The apology scenarios were adopted from the CCSARP Project (Blum-Kulka et al., 1989). DCT is a standard data elicitation procedure used in interlanguage pragmatics studies. Although the collected linguistic material does not come from naturalistic conditions, this method of data collection enables researchers to obtain a large data sample with a high frequency of the speech act under investigation. 
An anonymous online questionnaire was designed to collect the responses. It included four apology scenarios and four distractor scenarios which elicited other speech acts. This was done to ensure that respondents did not answer mechanically using the same forms for all apology scenarios. Following Olshtain (1989) and Suszczyńska (1999), the following scenarios were selected because of their universality across cultures:

1. You borrowed your professor's book, which you promised to return today, but you forgot to bring it (S1).

2. You are on a crowded bus. You put your shopping bag on the luggage rack, but when the bus stopped suddenly, your bag fell and hit another passenger (S2).

3. You are a manager. You kept a job applicant waiting for half an hour for a job interview because you had to go to an unexpected meeting (S3).

4. You are a student who is always late. Today, you are late again for a meeting with a friend. You were going to work on an assignment together (S4).

The link to the questionnaire was sent to all students enrolled in the three courses, but the participation was voluntary and the IP addresses were not stored. The participants were instructed to read each scenario carefully and provide a response they believed they would utter in the described circumstances. Because one participant's responses were off-topic and unclear, they were removed from the data set. In addition, a few of the respondents did not submit answers to some DCT items. As a result, a total of 428 apologies were included in the final analysis: 127 produced by Group 1, 148 produced by Group 2, and 153 produced by Group 3.

\subsection{Data analysis}

The data were coded using the apology coding procedures adopted from Blum-Kulka and Olshtain (1984), Blum-Kulka et al. (1989) and Rose (2000). Because performance of an apology can entail a use of multiple strategies, the first apology in each utterance was identified as the main strategy and assigned one of the following categories: (1) an IFID, (2) an explanation, (3) an expression of the offender's responsibility, (4) an offer of repair, (5) promise of forbearance, or (6) no apology. In addition, the IFIDs were classified into the 
following sub-categories depending on the performative verb used: (be) sorry, excuse, apologize, forgive, forget, and pardon. Any subsequent strategies identified in each utterance were coded as adjunct, and each was assigned one of the categories that were also used to code the main strategy. Lexical intensifiers were also examined as a part of the analysis.

Descriptive statistics illustrated with specific examples from the data are reported. In addition, one-way ANOVAs and Chi-square tests were run to determine if the differences noted between the groups were statistically significant.

\subsection{Research hypotheses}

It was hypothesized that Group 1 would show the smallest degree of main strategy diversification and the least use and diversification of auxiliary apology strategies because this group had received the least education in English and had had the least amount of English teaching experience. It was also hypothesized that due to extensive experience teaching English at school, Group 3 should perform similar to or slightly better than Group 2, who had less teaching experience but completed more credit units in English.

\section{$4 \quad$ RESULTS}

The first important finding is that, with respect to the main apology strategy, all three groups showed a strong preference for IFIDs (Figure 1). The following responses are examples of IFID usage:

1. Sorry I forgot to bring your book. (S1)

2. I'm sorry I kept you waiting. (S3) 


\section{Nordic Journal of Modern Language Methodology}

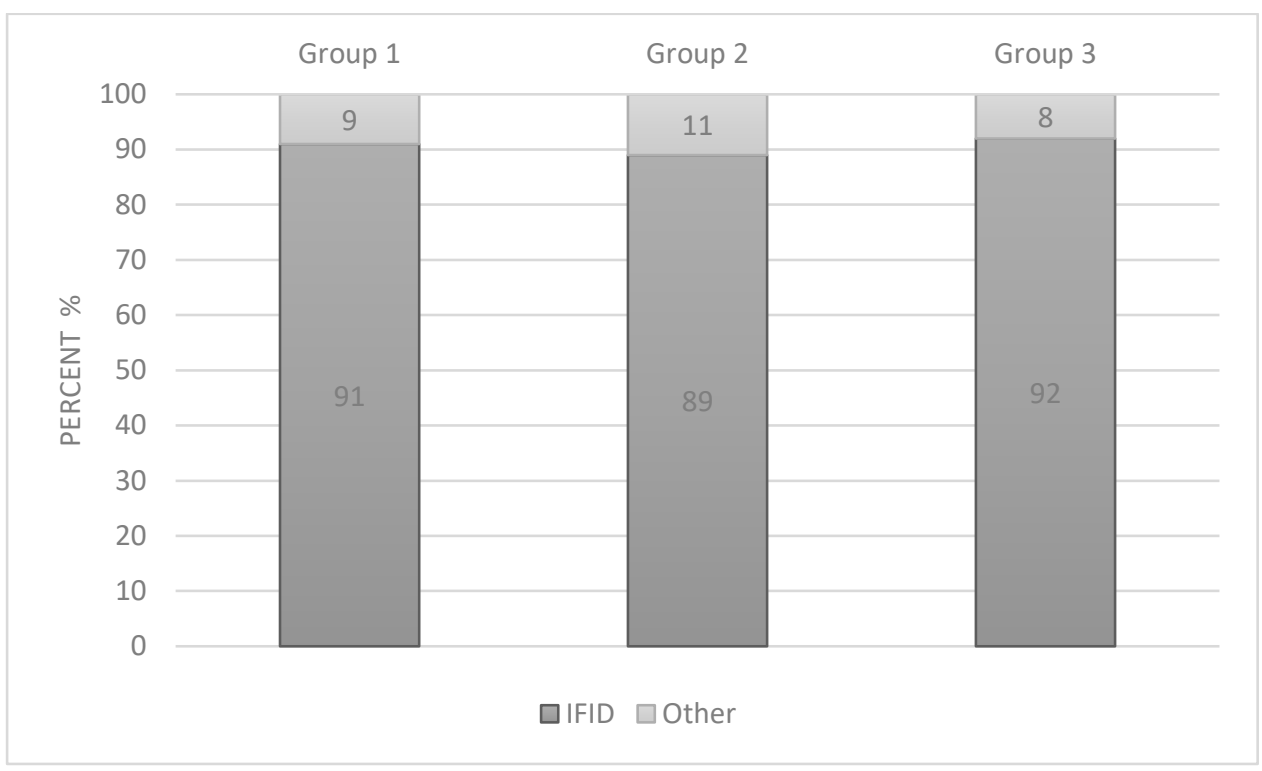

Figure 1: Percentage of main apology strategy

Very few of the responses included other main strategies, namely acknowledgments of responsibility, expressions of concern, explanations, promises of forbearance, or offers of repair. There was also one case of a response that did not contain an apology. The summary of all main strategies is presented in Table 1. The following examples illustrate other main strategies:

3. Hey professor, I know I promised to return the book today. (S1, Responsibility)

4. Are you ok? (S2, Concern)

Table 1: IFIDs and other strategies in the main apology

\begin{tabular}{|l|l|l|l|l|l|l|l|}
\hline Group & IFIDs & $\begin{array}{l}\text { Responsi } \\
\text { bility }\end{array}$ & Concern & $\begin{array}{l}\text { Explanat } \\
\text { ion }\end{array}$ & $\begin{array}{l}\text { Forbeara } \\
\text { nce }\end{array}$ & Repair & None \\
\hline Group 1, & $91 \%$ & $5 \%$ & $1.5 \%$ & $1.5 \%$ & --- & --- & $1 \%$ \\
\hline Group 2, & $89 \%$ & $6 \%$ & $4 \%$ & --- & $1 \%$ & --- & --- \\
\hline Group 3, & $91 \%$ & $6 \%$ & $2 \%$ & --- & --- & $1 \%$ & --- \\
\hline
\end{tabular}

A chi-square test was performed to examine whether there was a significant difference between the three groups in the use of IFIDs and other strategies employed as the main 


\section{Nordic Journal of Modern Language Methodology}

apology. No such difference was found, $\chi^{2}(2)=.787, p=.693$. Thus, this finding does not support the hypothesis that the participants who had received fewer credit hours in English and had had less teaching experience employ less diverse main apology strategies. Main strategy performance was fairly uniform across the groups.

By far the most commonly employed IFID was I'm sorry (Figure 2). The use of other IFIDs was minimal: of all IFIDs in the data, only $6 \%$ involved an alternative conventionalized expression of regret. Among those, the most common was I apologize (5\% of all IFIDs). The only other performative verbs identified in the responses were Excuse me and Pardon me, and both were used in responses to Scenario 2 (Bus).

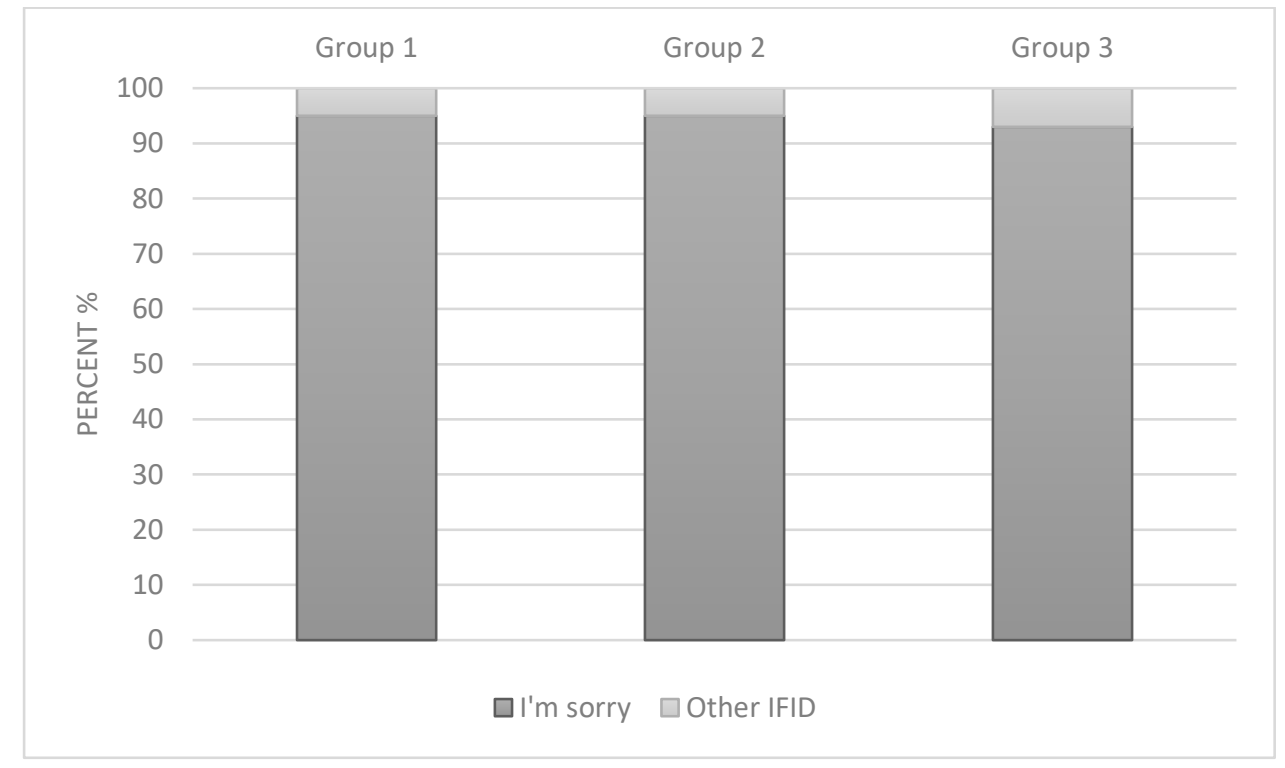

Figure 2: Percentage of IFIDs in the main apology

An examination of the Norwegian control data suggests a much more diversified use of main apology strategy. In addition to the IFID Beklager (I apologize), which constituted 60\% of the responses, other IFIDs such as Jeg er lei (I'm sorry) and Unnskyld ('excuse me') were also used. Other main strategies identified include an expression of concern (e.g., Gikk det bra?, Are you ok?), and an acknowledgement of responsibility (e.g., Dette er flaut, It's embarrassing).

In addition to the main apology strategy, most of the responses also contained adjunct strategies. In all, $84 \%$ of the responses contained modifications (Figure 3). In Group 1, the 


\section{Nordic Journal of Modern Language Methodology}

percentage was the lowest, with $72 \%$ of the responses employing other strategies than just the main apology. The numbers were higher for Group 2 (90\%) and Group 3 (88\%).

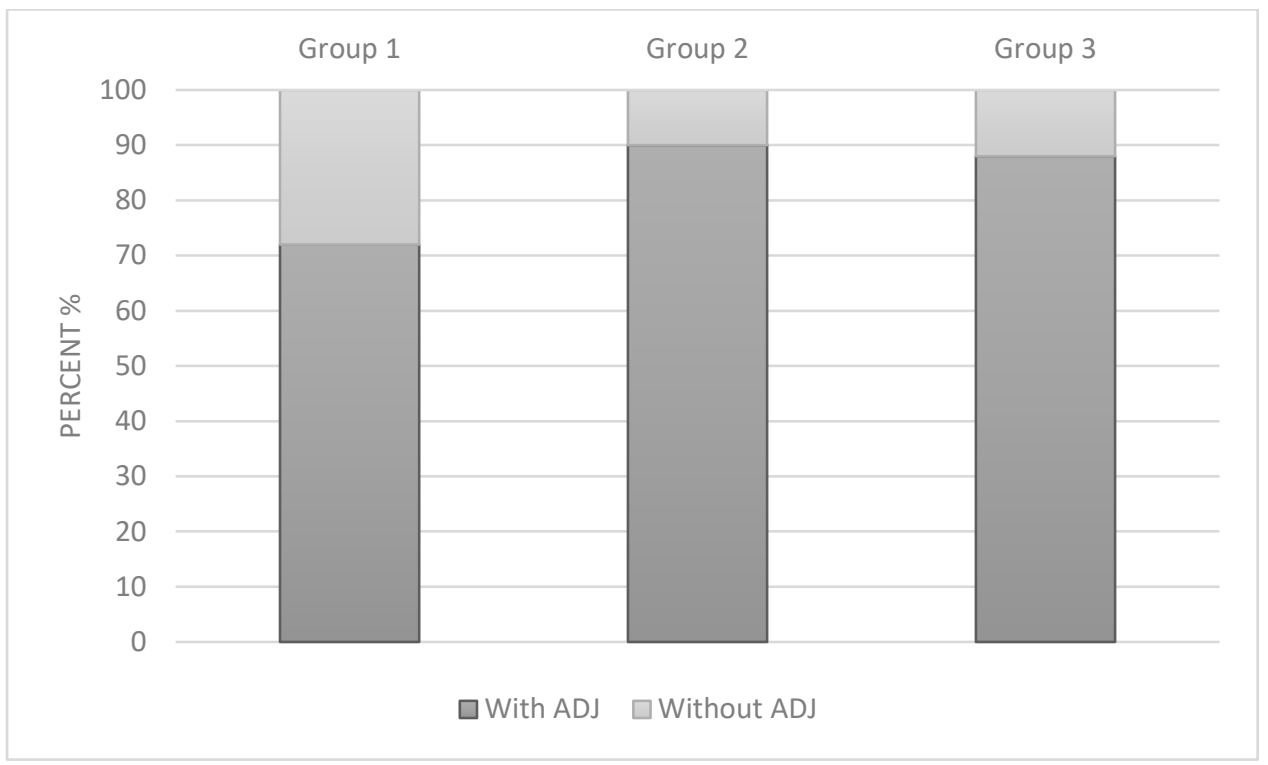

Figure 3: Percentage of responses containing adjunct strategies

The frequency of individual adjunct strategies as well as the diversity of adjunct strategies were also examined. The average number of strategies used per response increased across the three groups. Group 1 used the fewest modifications ( 0.9 on average), while Group 2 averaged 1.23 and Group 3 averaged 1.29 adjunct strategies per apology. The average number of adjunct strategies employed in the Norwegian control data was 1.08 strategies per response, i.e., somewhat higher than in Group 1 and somewhat lower than in Group 2 and Group 3. Figure 4 shows the increase in the average use of adjunct strategies per response in the English data. 


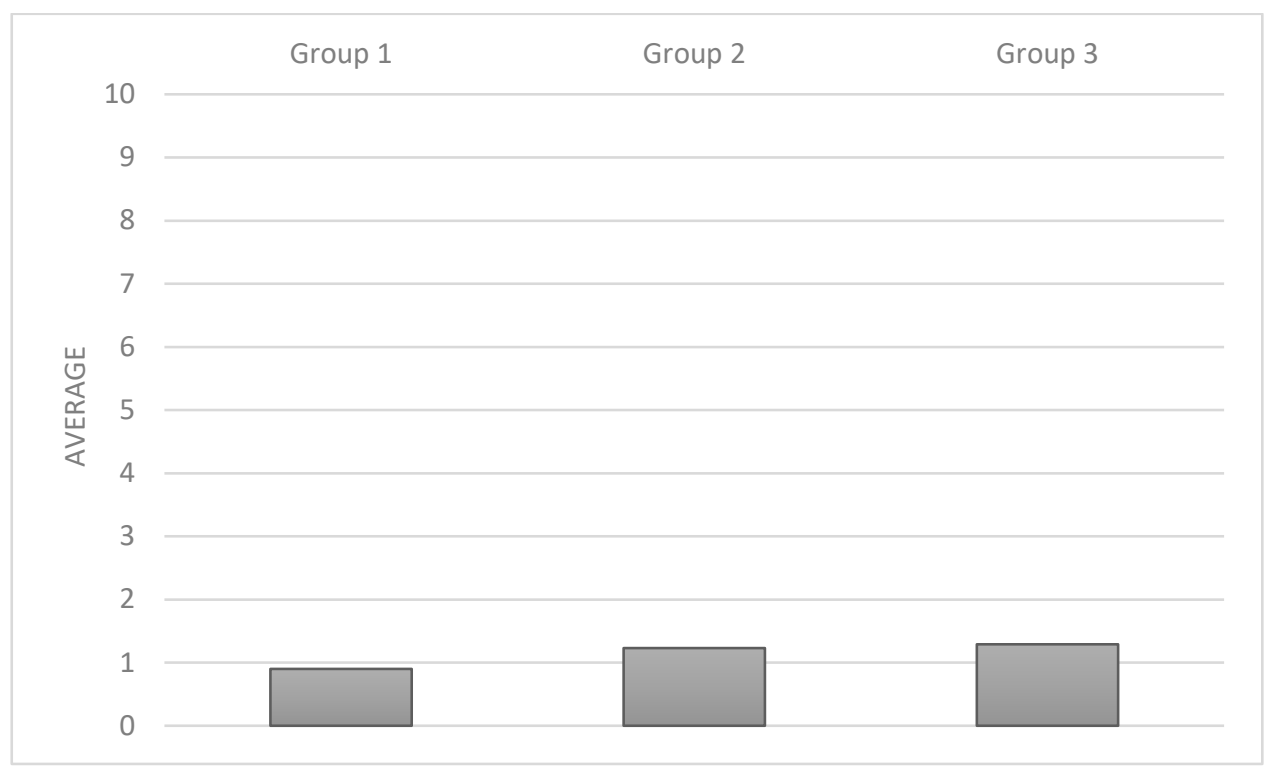

Figure 4: Average number of adjunct strategies per group.

A one-way ANOVA revealed that the differences in the average number of adjunct strategies used by the three groups were significant, $F(2,425)=12.17, p=.001, \omega=0.042$. Comparisons using Tukey's contrasts found a statistical difference between Group 1 and Group 2 (mean difference $=0.3,95 \% \mathrm{CI}=-0.1,-0.5, \mathrm{p}<.001$ ), and between Group 1 and Group 3 (mean difference $=0.3,95 \% \mathrm{CI}=-0.2,-0.6, \mathrm{p}<.001$ ). However, there was no statistically significant difference between Group 2 and Group 3 (mean difference $=0.1,95 \%$ $\mathrm{CI}=0.2,-0.3, \mathrm{p}=.767)$. These findings confirm the hypothesis that pre-service teachers with less teaching experience and fewer credit hours in English use fewer apology strategies than pre-service and in-service teachers who had received more credit hours or who had had more extensive teaching experience.

Overall, adjunct apology strategies were much more diversified than main apology strategies, and included various IFIDs, explanations, acknowledgements of responsibility, offers of repair, promises not to commit the offense again, and expressions of concern for the offended. Table 2 summarizes the number of occurrence of each of the types of adjunct strategies used by the three groups, and the following examples illustrate the adjunct strategies found in the data:

5. I hope you can forgive me today. (S4, IFID) 
6. My sense of time is horrible. (S4, Responsibility)

7. Did you get hurt? (S2, Concern)

8. I had to go to a very important meeting. (S3, Explanation)

9. I will try to do better next time. (S4, Promise)

10. I can come right back with it after class. (S1, Repair)

Table 2: Adjunct strategies

\begin{tabular}{|l|l|l|l|l|l|l|}
\hline Group & IFID & $\begin{array}{l}\text { Responsi } \\
\text { bility }\end{array}$ & Concern & $\begin{array}{l}\text { Explanat } \\
\text { ion }\end{array}$ & Promise & Repair \\
\hline Group 1 & 12 & 17 & 27 & 25 & 6 & 31 \\
\hline Group 2 & 17 & 24 & 36 & 48 & 14 & 38 \\
\hline Group 3 & 21 & 24 & 42 & 40 & 11 & 55 \\
\hline
\end{tabular}

A chi-square test was used to examine whether there was a significant difference between the three groups with respect to the types of adjunct strategies. Those responses that contained more than one adjunct strategy were coded as such for the purpose of this analysis. The association was significant, $\chi^{2}(14)=27.68, p=.016$. Thus, the three groups differed in not only the average number of adjunct strategies employed per apology, but also the types of adjunct strategies employed.

In those L2 responses which employed more than one adjunct strategy, stylistic variation was noted. More varied strategy combinations were found in the apologies produced by Group 2 and Group 3. These two groups also used longer strings of strategy combinations, with the longest one including four different strategies. Selected examples of utterances containing combined adjunct strategies are provided in excerpts 11-16. Note that the examples also include the main strategy.

Group 1 used the fewest adjunct strategy combinations, as well as the shortest utterance strings. The longest combinations contained two adjunct strategies.

11. I'm so sorry! It's just that sometimes I am so stressed when I'm about to get going somewhere that I forget to bring the most important things. I'll write it down so I'll remember to bring it tomorrow. (S1, Explanation + Repair) 
12. I'm terribly sorry! It was stupid of me to place my shopping bag on the rack. Are you hurt? (S2, Responsibility + Concern)

Group 2 used more varied strategy combinations in comparison with Group 1. They also used longer strings of various strategies, with the longest one consisting of three adjunct strategies.

13. I'm so sorry I forgot to bring your book today. I know I promised to bring the book back today. If it's okay I will bring it tomorrow. (S1, Responsibility + Repair)

14. Hi guys, sorry I'm late. Have you waited long? I got stuck in traffic today. So typical of me! (S4, Concern + Explanation + Explanation)

Group 3 used the most diversified adjunct strategy combinations, and also used combined strategies more frequently than the other two groups. The longest utterances consisted of the main strategy and four adjunct strategies.

15. Hello! I apologize so much for keeping you waiting! A meeting came up and it was a case that couldn't wait. Now you know a little bit how it is to work here, sometimes we just have to sort out some things and set other things on wait. Hope you got something to drink while waiting. (S3, Explanation + Explanation + Concern)

16. Oh, I am so sorry! Are you ok? Are you hurt in any way? I hope you can forgive me. I thought I placed it safely on the rack, but the bus suddenly stopped and threw it down anyway! (S2, Concern + Concern + IFID + Responsibility)

The Norwegian L1 data displayed fewer strategy combinations, suggesting that all three groups have acquired English apology patterns not present in their first language. The longest Norwegian L1 apology utterance contained a combination of three different strategies (three instances), but overall, only $18 \%$ of the responses contained more than one adjunct strategy.

Finally, the analysis of the use of lexical intensifiers in the responses was performed. Examples of the intensifiers found in the data include so, very, really, terribly, deeply, and 'incredibly.' $69 \%$ of the apologies contained lexical intensifiers (Figure 5). 


\section{Nordic Journal of Modern Language Methodology}

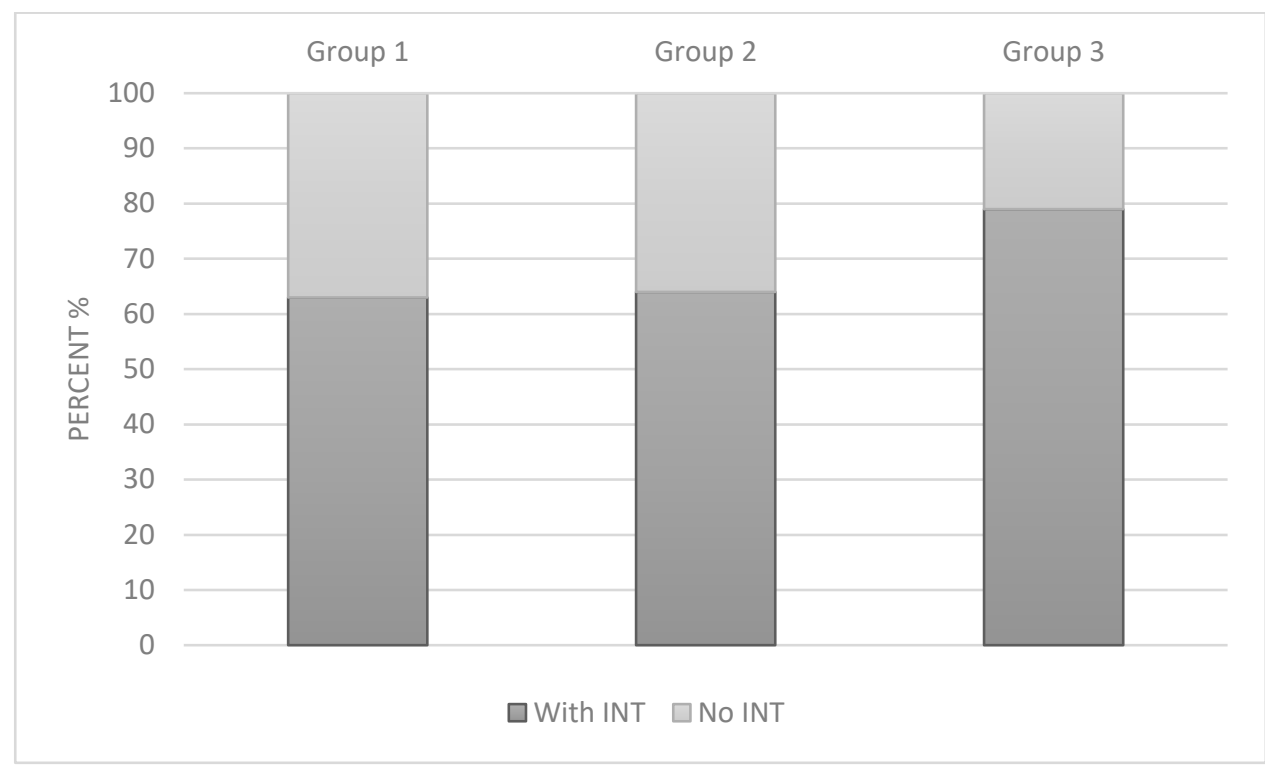

Figure 5: Percentage of responses containing intensifiers.

A one-way ANOVA found that the difference in the use of intensifiers between the groups was not significant, $F(2,425)=2.39, p=.09, \omega=0.006$. Only $19 \%$ of the responses in the Norwegian data contained intensifiers, suggesting again that L1 transfer cannot be used as an explanation for the strategies selected in L2.

\section{DISCUSSION AND CONCLUSION}

This study aimed to examine the differences in apology performance by three groups of Norwegian users of English: pre-service EFL teachers who had completed 30 ETCs in English, pre-service EFL teachers who completed 60 credit hours of English, and in-service English teachers who completed 30 credit hours in English. It was expected that the more advanced groups will use more diversified main apology strategies and a greater number and diversity of adjunct strategies.

The most significant finding is that the three groups of participants did not exhibit statistically significant differences in the main apology strategy selection. The main apology strategy most frequently chosen by all groups was the explicit illocutionary force indicating device I'm sorry. There were also no statistically significant differences in the use of intensifiers (e.g., very, extremely). In comparison with former studies (e.g., Cohen et al., 
1986), which found more variation in the use of main strategies by advanced English learners, the participants in this study seem to have overgeneralized the use of sorry, and underutilized other main strategies such as an acknowledgment of responsibility or an offer of repair. Other studies, however, obtained similar results to those found in the research reported here and concluded that there are no differences in the use of main apology strategies across proficiency levels (e.g., Rose, 2000). A comparison with the Norwegian data collected from the control group revealed a greater variety of the strategies employed in L1 suggesting that developmental factors rather than transfer are at play.

There was also no significant increase across the groups in the employment of apology intensifications. However, all groups used more lexical intensifiers than were found in the Norwegian L1 data. This suggests that all three groups have acquired the English convention to use intensifiers to appease the offendee (Márquez Reiter, 2000). Similar results were obtained by Sabaté i Dalmau and Curell i Gotor (2007).

Nevertheless, differences across the levels were found in the use of adjunct strategies. Both the average number of adjunct strategies per response as well as the types of adjunct strategies differed among the groups. There was more diversity in the use of adjuncts in Group 2 and Group 3 than in Group 1. On average, Group 1 used the fewest adjunct strategies, while Groups 2 and 3 used a similar average number of adjunct strategies per response. For instance, Group 2 and Group 3 used more expressions of concern for the offended (e.g., Are you alright?), acknowledgments of responsibility such as expressions of self-deficiency (e.g., I know that I'm always late), lack of intent (e.g., I did not think it would fall down), offers of repair (e.g., If you need it today, I can go fetch it), and promises of forbearance (e.g., I will get better, I promise). The increase in the average number of adjunct strategy use per response was statistically significant. This finding confirms the hypothesis that the teachers who received more training in English or had more teaching experience would outperform the teachers with less training and less teaching experience. These findings are consistent with previous research, which has found a marked increase in the use of apology adjuncts across proficiency levels (e.g., Rose, 2000), yet they also suggest that more advanced speakers can overuse the strategies that they have at their disposal. While on the one hand such extensive use of adjunct strategies may result from higher levels of L2 competence, it could be argued that some degree of redundancy is also observed, for example 
when the speaker expresses concern for the well-being of the offendee twice. Such verbosity, which can be interpreted as over-politeness, has been previously found in research on interlanguage pragmatics and has been associated with more advanced learners' interlanguage (Kasper \& Rose, 2002).

Much more work remains to be done in exploring the developmental differences in performance of apologies by second language learners. This study has shown that more advanced language users employ more adjunct strategies when performing apologies, but that a higher level of proficiency does not imply a more diversified performance of the main apology. The findings presented here should be validated using data collected through methods other than DCT, for example role-plays and naturally occurring apologies. Additionally, future research should also examine apologies by learners at various proficiency levels in a range of second languages and using a longitudinal design.

\section{REFERENCES}

Awedyk, W. (2011). On apologizing in Norwegian. Folia Scandinavica, 13, 50-62.

Aydin, M. (2013). Cross cultural pragmatics: A study of apology speech acts by Turkish speakers, American English speakers and advanced nonnative speakers of English in Turkey (Order No. 1538756). Available from ProQuest Dissertations \& Theses Global. (1400471894). Retrieved on April 1, 2015 from http://search.proquest.com/docview/1400471894?accountid=14677

Bachman, L. F. \& Palmer, A.S. (2010). Language assessment in practice: Developing language assessment and justifying their use in the real world. Oxford: Oxford University Press.

Bardovi-Harlig, K. \& Hartford, B. S. (1996). Input in an institutional setting. Studies in Second Language Acquisition, 18(2), 171-188.

Blum-Kulka, S., House, J. \& Kasper, G. (1989). Cross-cultural pragmatics: Requests and apologies. Norwood, NJ: Ablex.

Blum-Kulka, S. \& Olshtain, E. (1984). Requests and apologies: A cross-cultural study of speech act realization patterns (CCSARP). Applied Linguistics, 5(3), 196-213. 
Brown, P. \& Levinson, S. (1978). Universals of language use: politeness phenomena. In E. Goody (Ed.), Questions and politeness: strategies in social interaction (pp. 56-311). Cambridge: Cambridge University Press.

Brown, P. \& Levinson, S. (1987). Politeness. Some universals in language use. Cambridge, New York, NY: Cambridge University Press.

Cohen, A. D. (1996). Investigating the production of speech act sets. In S. M. Gass \& J. Neu (Eds.), Speech acts across cultures: Challenges to communication in a second language (pp. 21-43). Berlin: Mouton de Gruyter.

Cohen, A. D., Olshtain, E., \& Rosenstein, D. (1986). Advanced EFL apologies: what remains to be learned? International Journal of the Sociology of Language, 62(6), 51-74.

Cohen, A. D. \& Shively, R. L. (2007). Acquisition of requests and apologies in Spanish and French: Impact of study abroad and strategy-building intervention. The Modern Language Journal, 91(2), 189-212.

Cook, V. (1999). Going beyond the native speaker in language teaching. TESOL Quarterly, 33(2), 185-209.

Deutschmann, M. (2003). Apologising in British English. Umeå: Umeå University.

Ellis, R. (2003). The study of second language acquisition. Oxford: Oxford University Press.

Fraser, B. (1981). On apologizing. In F. Coulmas (Ed.), Conversational routine. Explorations in standardized communication situations and prepatterned speech (pp. 259-273). The Hague: Mouton.

Goffman, E. (1967). Interactional Ritual: Essays on face-to-face behavior. Garden City, NY: Anchor Books.

Holmes, J. (1990). Apologies in New Zealand English. Language in Society, 19(2), 155-199. Ishihara, N. (2010). Lesson planning and teacher-led reflection. In N. Ishihara \& A. Cohen (Eds.), Teaching and learning pragmatics. Where language and culture meet (pp. 186200). Great Britain: Longman Applied Linguistics.

Kasper, G. \& Rose, K. (2002). Pragmatic development in a second language. Oxford, Malden: Blackwell Publishing.

Kim, I.-O. (2000). Relationship of onset age of ESL acquisition and extent of informal input to appropriateness and nativeness in performing four speech acts in English: A study of 
native Korean adult speakers of ESL. (Doctoral dissertation, New York University). Dissertation Abstracts International, 61, 1265.

Kondo, S. (1997). The development of pragmatic competence by Japanese learners of English; longitudinal study on interlanguage apologies. Sophia Linguistica, 41, 265284.

Leech, G. (1980), Explorations in Semantics and Pragmatics. Amsterdam: Benjamins.

Llurda, E. (2004). Non-native-speaker teachers and English as an International Language. International Journal of Applied Linguistics, 14(3), 314-323.

Maeshiba, N., Yoshinaga, N., Kasper, G., \& Ross, K. (1996). Transfer and proficiency in interlanguage apologizing. In S. M. Gass \& J. Neu (Eds.), Speech acts across cultures: Challenges to communication in a second language (pp. 155-187). Berlin: Mouton de Gruyter.

Márquez Reiter, R. (2000). Linguistic politeness in Britain and Uruguay: A contrastive study of requests and apologies. Amsterdam, Philadelphia: John Benjamins.

Ogiermann, E. (2009). Politeness and in-directness across cultures: A comparison of English, German, Polish and Russian requests. Journal of Politeness Research, 5(2), 189-216.

Ohta, A. S. (1995). Applying sociocultural theory to an analysis of learner discourse: Learner-learner collaborative interaction in the zone of proximal development. Issues in Applied Linguistics, 6(2), 93-121.

Olshtain, E. (1989). Apologies across languages. In S. Blum-Kulka, J. House \& G. Kasper (Eds.), Cross-cultural pragmatics: Requests and apologies (pp. 155-173). Norwood, $\mathrm{NJ}$ : Ablex.

Olshtain, E., \& Cohen, A. D. (1986). Apology: a speech act set. In N. Wolfson \& E. Judd, (Eds.), Sociolinguistics and language acquisition (pp. 18-35). Rowley, MA: Newbury House.

Rose, K. R. (2000). An exploratory cross-sectional study of interlanguage pragmatic development. SSLA, 22(1), 27-67.

Rose, K. R. (2009). Interlanguage pragmatic development in Hong Kong, phase 2. Journal of Pragmatics, 41(11), 2345-2364. 
Sabaté i Dalmau, M. S, \& Curell i Gotor, H. C. (2007). From "Sorry very much" to "I'm ever so sorry": Acquisitional patterns in L2 apologies by Catalan learners of English. Intercultural Pragmatics, 4(2), 287-315.

Searle, J. R. (1969). Speech acts: an essay in the philosophy of language. Cambridge University Press: Cambridge.

Suszczyńska, M. (1999). Apologizing in English, Polish and Hungarian: Different languages, different strategies. Journal of Pragmatics, 31(8), 1053-1065.

Takahashi, S. (2001). The role of input enhancement in developing pragmatic competence. In K. R. Rose \& G. Kasper (Eds.), Pragmatics in language teaching (pp. 171-199). New York: Cambridge University Press.

Trosborg, A. (1987). Apology strategies in natives/non-natives. Journal of Pragmatics, 11(2), 147-167.

Utdanningsdirektoratet (2006). Knowledge Promotion: Primary and lower secondary education. Retrieved on April 1, 2015, from:

http://www.udir.no/Stottemeny/English/Curriculum-in-English/Curricula-in-English/. 